\title{
Underdiagnosis of frontotemporal lobar degeneration in Brazil
}

\author{
Valéria Santoro Bahia
}

\begin{abstract}
Frontotemporal lobar degeneration (FTLD) is a progressive neurodegenerative disorder that involves the frontal and anterior temporal lobes. It is characterized by prominent behavioral and language disorders. There are three variants of FTLD: frontotemporal dementia (FTD), semantic dementia (SD) and progressive non-fluent aphasia (PNFA). FTLD may be mistaken for AD (Alzheimer's disease) or psychiatric disorders especially in the early stages. Objectives: To describe the demographic characteristics of patients with FTLD, assessed at the Behavioral and Cognitive Neurology Unit, and to show that FTLD is commonly clinically under-diagnosed. Methods: All patients diagnosed with FTLD (Consensus Criteria for FTLD), and who were seen at the Behavioral and Cognitive Neurology Unit of Hospital das Clínicas, in São Paulo, Brazil from January 2004 to August 2007 were included in the analyses. Results: Sixteen patients with FTLD (11 women) were included in this study. There were 12 patients with FTD, two with PNFA and two with SD. The mean duration of the illness until diagnosis of FTLD was $4.1 \pm 2.3$ years, ranging from one to seven years. Nine patients had been initially seen by psychiatrists, five by neurologists, and two by general physicians. The first diagnosis was psychiatric disorder in six patients, $\mathrm{AD}$ in four, dementia in two, FTD in two, and stroke and hydrocephalus for one patient each. Conclusion: The diagnosis of FTLD can be difficult and many patients may be misdiagnosed in Brazil, especially in the initial stages. Educational programs on FTLD for the medical community are warranted.
\end{abstract}

Key words: frontotemporal lobar degeneration, frontotemporal dementia, Alzheimer's disease, semantic dementia, primary progressive aphasia.

\begin{abstract}
Subdiagnóstico de degeneração lobar fronto-temporal no Brasil
Resumo - Degeneração Lobar Fronto-temporal (DLFT) é uma doença neurodegenerativa progressiva que acomete lobos frontais e temporais. Caracteriza-se pela predominância de distúrbios comportamentais e de linguagem. Há três variantes da DLFT: demência fronto-temporal (DFT), demência semântica (DS) e afasia progressiva não fluente (APNF). Pacientes com DLFT podem ser diagnosticados erroneamente, principalmente nas fases iniciais. Objetivos: Descrever as características demográficas dos pacientes avaliados no Grupo de Neurologia Cognitiva e do Comportamento e mostrar que os casos de DLFT são freqüentemente diagnosticados erroneamente em fase inicial. Métodos: Avaliamos todos os indivíduos com o diagnóstico de DLFT, (Critérios de Consenso de DLFT) atendidos no Grupo de Neurologia Cognitiva e do Comportamento do Hospital das Clínicas, São Paulo, Brasil, entre Janeiro de 2004 e Agosto de 2007. Resultados: Foram incluídos 16 pacientes com DLFT (11 mulheres). Doze pacientes tiveram o diagnóstico de DFT, dois de DS e dois APNF. A média de duração

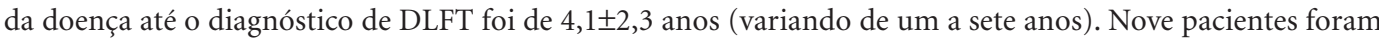
avaliados, no início da doença, por psiquiatras, cinco por neurologistas e dois por clínicos gerais. O primeiro diagnóstico foi de distúrbio psiquiátrico em seis pacientes, DA em quatro pacientes, demência em dois, DFT em dois, acidente vascular cerebral em um e hidrocefalia em um paciente. Conclusão: O diagnóstico de DLFT pode ser difícil e muitos pacientes, principalmente em fases iniciais, podem estar sendo diagnosticados erroneamente no Brasil. Há a necessidade de maior informação sobre a doença na comunidade médica.

Palavras-chave: degeneração lobar fronto-temporal, demência fronto-temporal, doença de Alzheimer, demência semântica, afasia progressiva primária.
\end{abstract}

MD, PhD Brazil. Behavioral and Cognitive Neurology Unit, Department of Neurology, Hospital das Clínicas, University of São Paulo School of Medicine, São Paulo.

Valeria Santoro Bahia - Rua Conselheiro Brotero, 1505 / cj. 52 - 01232-011 São Paulo SP - Brazil.

Received 10/25/2007. Received in final form 11/05/2007. Accepted 11/18/2007. 
Frontotemporal lobar degeneration (FTLD) is a progressive neurodegenerative disorder that involves the frontal and temporal lobes. It is characterized by prominent and gradual behavioral and language disorders, whereas memory is relatively preserved. ${ }^{1,2}$

FTLD is the second most common cause of degenerative dementia after Alzheimer's disease (AD) in the presenile period (45-65 years) having a low prevalence in the elderly. ${ }^{3-6}$ In a study of the prevalence of dementia in a community-dwelling population, aged 65 years or more living in Catanduva, Brazil only $2.5 \%$ of the demented patients had the diagnosis of FTD. ${ }^{7}$

Neary et al. ${ }^{1}$ distinguished three variants of FTLD with hallmark sets of presenting symptoms and regional patterns of atrophy: the frontal variant of frontotemporal dementia (FTD), semantic dementia (SD) and progressive non-fluent aphasia (PNFA).

FTD is the most common clinical presentation, and accounts for approximately half of all FTLD diagnoses. The characteristic features include loss of insight, disinhibition, impulsivity, apathy, reduced empathy for others, poor self care, stereotypic behavior, emotional blunting, and changes in eating patterns. ${ }^{5,8}$

Two other clinical subtypes of FTLD have been characterized for the most prominent symptoms of the language dysfunction. PNFA is a disorder of expressive language, including nonfluent spontaneous speech and word retrieval difficulties with phonological and grammatical errors. SD is a disorder characterized by progressive loss of knowledge on words and objects in which fluency of speech is maintained, along with agnosia for faces and objects. PNFA and particularly SD, tend to aggregate behavioral abnormalities over the course of the disease. ${ }^{9-11}$

Diagnosis of FTD, PNFA and SD are not straightforward, often being mistaken for $\mathrm{AD}$ or psychiatry disorders, especially in the early stages. ${ }^{12-15}$

The objective of this study was to describe the demographic characteristics of the patients with FTLD assessed at the Behavioral and Cognitive Neurology Unit and to show that FTLD is usually clinically under-diagnosed.

\section{Methods}

All patients who fulfilled consensus criteria ${ }^{1}$ for FTLD (FTD, SD, APNF) and seen from January 2004 to August 2007 at the Behavioral and Cognitive Neurology Unit of Hospital das Clínicas, in São Paulo, Brazil were included in the study, where all subjects were evaluated by neurologists and neuropsychologists.

The diagnosis was based on anamneses, neurological examination, and neuropsychological assessment that included the Brief Cognitive Battery, ${ }^{16}$ Mattis Dementia Rat- ing Scale (DRS), ${ }^{17}$ Frontal Assessment Battery (FAB).${ }^{18}$ Activities of daily living were evaluated using the Functional Activities Questionnaire (FAQ). ${ }^{19}$

All patients underwent structural neuroimaging (CT or MRI) and functional SPECT imaging along with a battery of routine screening blood tests.

The age at onset was defined as the age at which the first symptom compatible with the diagnosis FTLD appeared as reported by the principal informant, while the duration of illness was defined by the interval between age at onset and age on first assessment. Education was considered as the number of years of formal education.

Descriptive statistics analyses were conducted using BioEstat 3.0 software.

\section{Results}

Sixteen patients, 5 men and 11 women, with mean age of $57.6 \pm 6.7$ years, mean age at onset of $53.6 \pm 7.8$ years (ranging from 36 to 63 years) and mean years of schooling of $8.0 \pm 6.2$ were included. Overall, FTD was the most common diagnosis, accounting for 12 patients, followed by SD and PNFA with two patients each.

Five patients were not submitted to neuropsychological assessment due to severity of the illness.

The mean MMSE score was $13.7 \pm 9.9$ and for FAQ was 22.7 \pm 7.5 .

The mean interval between the first symptom and the first structural neuroimage was $2.6 \pm 2.4$ years, and for the first SPECT was 3.0 \pm 2.4 years. The structural neuroimages (CT or MRI) were compatible with the diagnosis in $87.5 \%$ of the cases, and the SPECT in the $81.3 \%$. Only one patient, with a very typical clinical picture of FTD presented diffuse atrophy on MRI and diffuse cortical irregularities on SPECT.

The duration of illness until diagnosis of FTLD was $4.1 \pm 2.3$ years.

Nine patients had been initially seen by psychiatrists, five by neurologists and two by general physicians (Figure 1).

The first symptom was language dysfunction in four patients, apathy in three, stereotypic behavior in three, disinhibition in three, inattention in two, and obsessive symptoms in one patient (Figure 2).

The first diagnosis was psychiatric disorder in six patients, $\mathrm{AD}$ in four patients, dementia in two patients, FTD in two, and stroke and hydrocephalus for one patient each (Figure 3).

\section{Discussion}

In our sample, all patients presented early onset of the disease and $87.5 \%$ of the patients were misdiagnosed for $4.1 \pm 2.3$ years after the first symptoms. Structural and 


\section{General physician}

$19 \%$

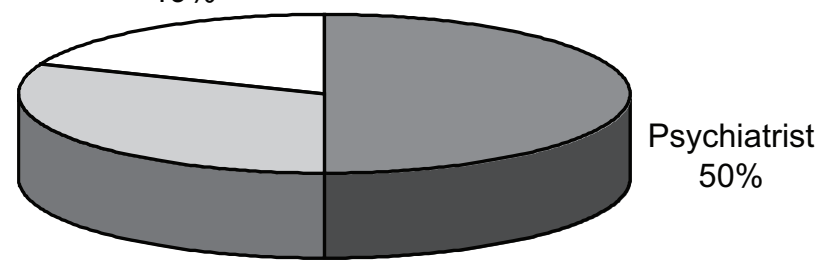

Neurologist

$31 \%$

Figure 1. First specialist to see patients.

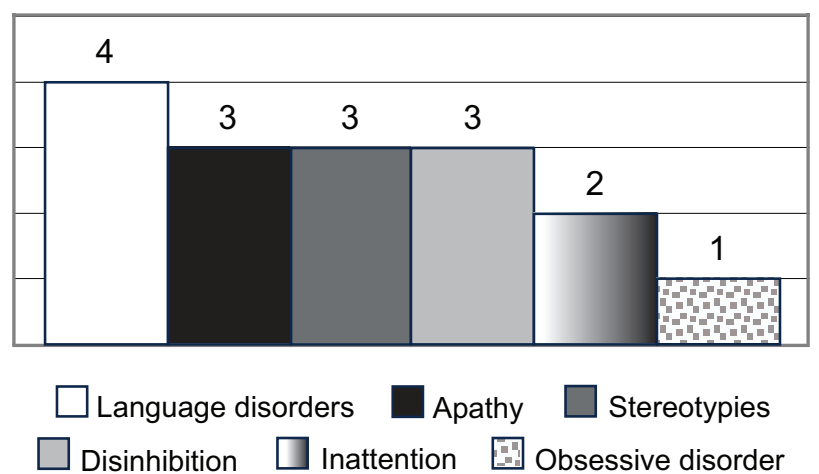

Figure 2. First symptom of the disease.

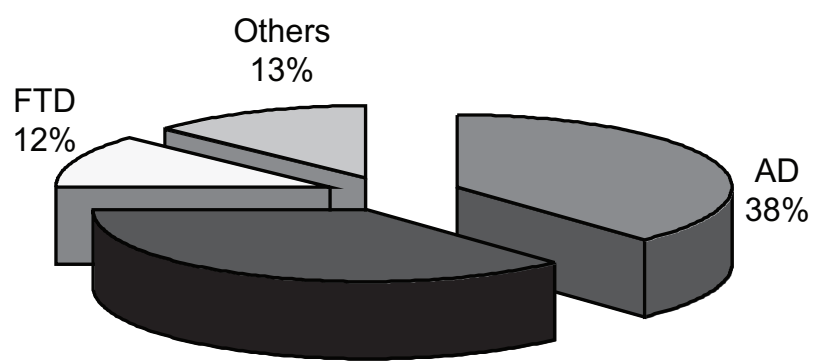

Psychiatry disorders $37 \%$

Figure 3. First diagnosis of the patients. AD: Alzheimer's disease; FTP: frontotemporal dementia.

functional neuroimaging was performed only after 2.6 2.2 .4 years and $3.0 \pm 2.4$ years, respectively. Consequently, these patients had delayed diagnoses and risked inappropriate therapy.

In general, the earliest manifestation of FTLD are behavioral changes, executive dysfunctions or language disorders while for $\mathrm{AD}$ there is a predominance of impaired episodic memory and visuospacial skills. ${ }^{12}$
Some FTLD patients have memory complaints, usually related to the disexecutive syndrome or to word finding difficulties from language dysfunction, ${ }^{12,13}$ although there are some evidences of hippocampal atrophy in SD and FTD patients. ${ }^{20-22}$

Despite these differences in neuropsychological profiles, there are evidences that clinical differentiation between FTLD and AD remains poor. A study using the NINCDSADRDA (National Institute for Communicative Disorders and Stroke - Alzheimer's Disease and Related Disorders Association) for a differential diagnosis between probable $\mathrm{AD}$ and FTD showed high sensitivity (0.93) but low specificity (0.23). In the cited study, twenty patients with pathological confirmation of FTD fulfilled criteria for AD. ${ }^{14}$

Rosen et al. ${ }^{12}$ performed a retrospective study comparing the initial presentation of $30 \mathrm{FTLD}$ patients and $30 \mathrm{AD}$ patients, and showed that $63 \%$ of the patients with FTLD were correctly identified at the initial clinical evaluation using consensus criteria. ${ }^{1}$ Five clinical features, including the presence of social conduct disorders, hyperorality, and akinesia, as well as absence of amnesia and absence of perceptual disorders, allowed the identification of $93 \%$ of the FTLD and $97 \%$ of the $\mathrm{AD}$ patients.

Mendez et al. ${ }^{15}$ compared the sensitivities and specificities of different diagnostic methods while investigating 134 patients with suspected FTD. The clinical diagnosis based on the consensus criteria ${ }^{1}$ attained sensitivity of $36.5 \%$ and specificity of $100 \%$, being $63.5 \%$ and $70.4 \%$ for structural neuroimage, and $90.5 \%$ and $74.6 \%$ for SPECT/PET scan, respectively. They demonstrated that neuropsychological results did not distinguish FTD from other causes of dementia, but the pattern of progression helped to establish the diagnosis after two years of follow up.

In our sample, after language disorders, which are the most frequent symptoms in patients with progressive aphasia (SD and PNFA), aberrant motor behavior (perseverative and compulsive behaviors), apathy and disinhibition were the most frequent first symptoms. These symptoms occur more frequently in FTLD than AD patients. ${ }^{23-25}$ Due to this, there are studies that advocate the use of behavioral scales in differential diagnosis between FTD and AD, and are considered better than neuropsychological tests. ${ }^{26,27}$

Physicians continue to experience difficulty in diagnosing early FTD because patients with behavioral changes are often referred to psychiatry services with suspected diagnosis of depression, personality disorders or schizophrenia, in spite of the low prevalence of psychotic symptoms in FTD. ${ }^{28}$

Schizophrenic patients may show a wide range of cognitive impairments, most prominently deficits in memory, executive functions, ${ }^{29}$ disorientation and impaired daily living skills. ${ }^{30}$ There is a lack of structured psychiatry assess- 
ment in differentiating psychiatric diseases from FTLD. ${ }^{31}$ There are few reports of cases of FTLD misdiagnosed as schizophrenia but in all such cases the structural neuroimaging exam confirmed the diagnosis of FTLD although carried out in delayed phase..$^{32-34}$

Our study has some methodological limitations. First, it was a retrospective study, and in some cases specific features may not have been reported by the caregiver. Second, the study lacked autopsy confirmation.

In conclusion, many patients with FTLD may be misdiagnosed, especially in the initial stages. FTLD should be distinguished from psychiatric disorders, $\mathrm{AD}$ and others dementias, because there are differences in treatment and prognosis. This differentiation can be difficult and demands an astute qualitative analysis of behaviors and neuropsychological test performances in conjunction with analyses of neuroimaging exams together with information from relatives. Provision of more information on FTLD to the medical community in Brazil is warranted.

\section{References}

1. Neary D, Snowden JS, Gustafson L, et al. Frontotemporal lobar degeneration. A consensus on clinical diagnostic criteria. Neurology 1998;51:1546-1554.

2. Neary D, Snowden J, Mann D. Frontotemporal dementia. Lancet Neurol 2005;4:771-780.

3. Ratnavalli E, Brayne C, Dawson K, Hodges JR. The prevalence of frontotemporal dementia. Neurology 2002;58:1615-1621.

4. Rosso SM, Kaat LD, Baks T, et al. Frontotemporal dementia in The Netherlands: patient characteristics and prevalence estimates from a population-based study. Brain 2003;126:20162022.

5. Johnson JK, Dichl J, Mendez MF, et al. Frontotemporal lobar degeneration. Demographic characteristics of 353 patients. Arch Neurol 2005;62:925-930.

6. Harvey RJ, Skelton-Robinson M, Rossor MN. The prevalence and causes of dementia in people under the age of 65 years. J Neurol Neurosurg Psychiatry 2003;74:1206-1209.

7. Herrera E Jr, Caramelli, Silveira AS, Nitrini R. Epidemiologic survey of dementia in a community-dwelling Brazilian population. Alzheimer Dis Assoc Disord. 2002;16:103-108.

8. Snowden JS, Neary D, Mann DMA. Frontotemporal dementia. Br J Psychiatry 2002;180:140-143.

9. Snowden JS, Bathgate D, Varma A, Blackshaw A, Gibbons ZC, Neary D. Distinct bahavioral profiles in frontotemporal dementia and semantic dementia. J Neurol Neurosurg Psychiatry 2001;70:323-332.

10. Gorno-Tempini ML, Dronkers NF, Rankin KP et al. Cognition and anatomy in three variants of primary progressive aphasia. Ann Neurol 2004;55:335-46.

11. Rosen HJ, Allison SC, Ogar JM, et al. Behavioral features in semantic dementia vs other forms of progressive aphasias. Neurology 2006;67:1752-1756.

12. Rosen HJ, Hartikainen KM, Jagust W, et al. Utility of clinical criteria in differentiating frontotemporal lobar degeneration (FTLD) from AD. Neurology 2002;58:1608-1615.

13. Liscic RM, Storandt M, Cairns NJ, Morris JC. Clinical and Psychometric distinction of frontotemporal and Alzheimer dementias. Arch Neurol 2007;64:535-540.

14. Varma AR, Snowden JS, Lloyd JJ, Talbot PR, Mann DMA, Neary D. Evaluation of the NINCDS-ADRDA criteria in the differentiation of Alzheimer's disease and frontotemporal dementia. J Neurol Neurosurg Psychiatry 1999;66:184-188.

15. Mendez MF, Shapira JS, McMurtray A, Licht E, Miller B. Accuracy of the clinical evaluation for frontotemporal dementia. Arch Neurol 2007;64:830-835.

16. Nitrini R, Lefèvre BH, Mathias SC, et al. Testes neuropsicológicos de aplicação simples para o diagnóstico de demência. Arq Neuropsiquiatr 1994;52:457-465.

17. Mattis S. Mental Status Examination for Organic Mental Syndrome in the Elderly Patient. In: Bellak L, Karasu TB, editors. Geriatric Psychiatry. A Handbook for Psychiatrists and Primary Care Physicians. New York: Grune \& Stratton; 1976:77-121.

18. Dubois B, Slachevsky A, Litvan I, Pillon B. The FAB: A Frontal Assessment Battery at bedside. Neurology 2000;55: 1621-1626.

19. Pfeffer RI, Kusosaki TT, Harrah Jr CH, Chance JM, Filos S. Measurement of functional activities in older adults in the community. J Gerontol 1982;37:323-329.

20. Caine D, Patterson K, Hodges JR, Heard R, Halliday G. Severe anterograde amnesia with extensive hippocampal degeneration in a case of rapidly progressive frontotemporal dementia. Neurocase 2001;7:57-64.

21. Galton CJ, Patterson K, Graham K, et al. Differing patterns of temporal atrophy in Alzheimer's disease and semantic dementia. Neurology 2001;57:216-225.

22. Graham A, Davies R, Xuereb J, et al. Pathologically proven frontotemporal dementia presenting with severe amnesia. Brain 2005;128:597-605.

23. Bozeat S, Gregory CA, Lambon Ralph MA et al. Which neuropsychiatry and behavioural features distinguish frontal and temporal variants of frontotemporal dementia from Alzheimer's disease? J Neurol Neurosurg Psychiatry 2000;69: 178-186.

24. Nyatsanza S, Shetty T, Gregory C, Dawson K, Hodges JR. A study of stereotypic behaviours in Alzheimer's disease and frontal and temporal variant frontotemporal dementia. J Neurol Neurosurg Psychiatry 2003;74:1398-1402.

25. Shinagawa S, Ikeda M, Fukuhara R, Tanabe H. Initial symptoms in frontotemporal dementia and semantic dementia compared with Alzheimer's disease. Dement Geriatr Cogn Disord 2006;21:74-80. 
26. Kertesz A, Davidson W, McCabe P, Munoz D. Behavioral quantitation is more sensitive than cognitive testing in frontotemporal dementia. Alzheimer Dis Assoc Disord 2003;17: 223-229

27. Hutchinson AD, Mathias JL. Neuropsychological deficits in frontotemporal dementia and Alzheimer's disease: a metaanalytic review. J Neurol Neurosurg Psychiatry. 2007;78: 917-928.

28. Diehl-Schmid J, Pohl C, Perneczky R, Förstl H, Kurz A. Behavioral disturbances in the course of frontotemporal dementia. Dement Geriatr Cogn Disord 2006;22:352-357.

29. Saykin AJ, Gur RC, Gur RE, et al. Neuropsychological function in schizophrenia: selective impairment in memory and learning. Arch Geriatr Psychiatry 1991;48:618-624.

30. Vries PJ, Honer WG, Kemp PM, McKenna PJ. Dementia as a complication of schizophrenia. J Neurol Neurosurg Psychiatry 2001:70:588-596.

31. Oliveira-Souza R, Marrocos RP, Moll J. The dementias of schizophrenia. Dement Neuropsychol 2007;2:124-30.

32. Waddington JL, Youssef HA, Farrel MA, Toland J. Initial 'schizophrenia-like' psychosis in Pick's disease: case study with neuroimaging and neuropathology, and implications for frontotemporal dysfunction in schizophrenia. Schizophrenia Research 1995;18:79-82.

33. Stone J, Griffiths TD, Rastogi S, Perry RH, Cleland PG. NonPicks frontotemporal dementia imitating schizophrenia in a 22-year-old man. J Neurol 2003;250:369-370.

34. Kitabayashi Y, Otakara C, Hirosawa R, Narumoto J, Fukui K. Frontotemporal dementia complicated with schizophrenia. Psychiatry and Clinical Neurosciences 2005;59:749-750. 